\title{
MICROSTRIP CIRCULAR PATCH ARRAY ANTENNA FOR ELECTRONIC TOLL COLLECTION
}

\author{
S.Sudharani ${ }^{1}$, P. Rakesh Kumar ${ }^{2}$ \\ ${ }^{1}$ Assistant Professor, Department of ECE, MIC college of technology, kanchikacherla, Krishna (DT) \\ ${ }^{2}$ Assistant Professor, Department of ECE, LBRC of Engineering-Autonomous, Mylavaram, AP, India
}

\begin{abstract}
Electronic toll collection will reduce the wastage of time at toll gates and collects the money in fast manner. At toll collection stations on the highway, the automatic toll collection will collect the money using one sensing antenna and the signal processing unit with the help of computer interfacing. The technology will reduce the man power usage, time and cost with customer friendly environment. The present paper deals with the design and analysis of electronic toll collection antenna operating at $5.8 \mathrm{GHz}$ with moderate gain and bandwidth. An array of 6 X6 elements patch antenna is used in this design, which increased the gain considerably for the desired operation.
\end{abstract}

Keywords: Parallel Feeding, Electronic Toll Collection (ETC), Microstrip Patch Array.

\section{INTRODUCTION}

The Electronic Toll Collection (ETC) is a technology that permits vehicles to pay highwaytolls electronically. This automation has replaced live attendants at toll stations that collect fees manually. Electronic Toll Collection is a concept that is being readily accepted globally. Some tags are designed to communicate with other kinds of roadside readers as well, making interstate and intrastate toll payments accessible. Toll agencies are interested in developing these tags and readers because they can simplify the tolling system [1-4].

The type of automatic vehicle identification tag signal that is most commonly used for electronic toll collection is radio frequency. While other types of signals such as laser and infrared (IR) have been tested and deployed, Radio Frequency tags currently provide the most accurate results. Automatic vehicle identification tags can be further broken down into distinct tag types based on the degree to which they can be programmed and the type of power source [5-8].

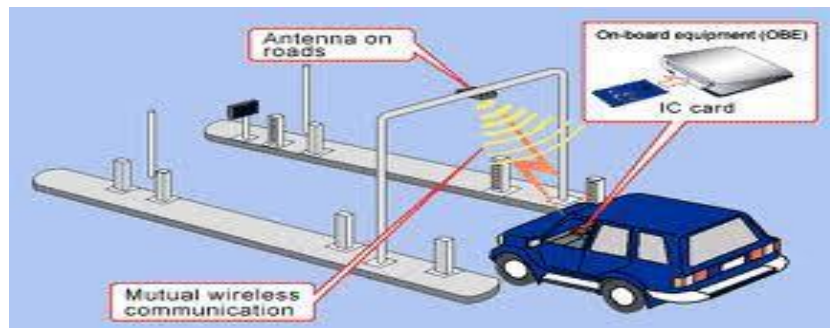

ETC system's can wireless communication and information change by the device fixed in the vehicle and road head device which was fixed in the toll station's roadway. It composes by automatic vehicle identification system, centre control system and other ancillary facilities. The system of automatic identification vehicle is composed by on board unit, road side unit, loop sensor and other components. And the centre control system is consisted of large database and the information of enrolled vehicles and users. When vehicle pass the toll station gob, loop sensor apperceive the vehicle; RSU sends out question signal; then OUB responds and done twoway communication and data exchange [9]. Centre control system fetch the identify vehicle information like as car's ID and car's module and compare these information to the database. According to situation, it controls the center manager system do different operation. Such as computer charge manager system deducts these travelling expenses from his bank count or send instruct to other assistant establishment. That realizes automatism management to running vehicle. Other assistant establishment mainly closed camera system of breaking vehicle, control railings, traffic instructions to the traffic equipment [10].

\section{ANTENNA DESIGN AND SPECIFICATION:}

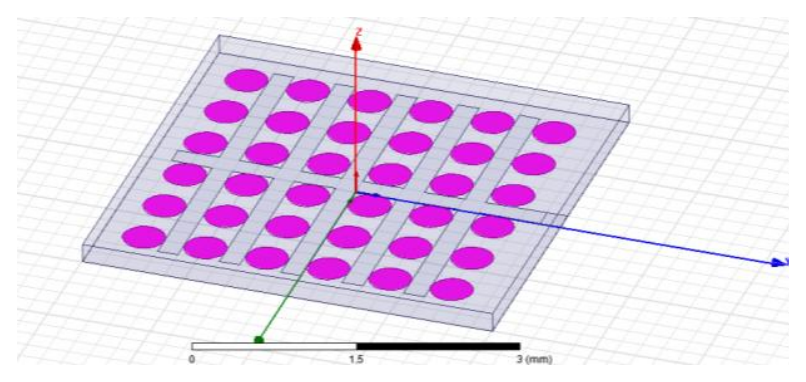

Figure 16 X6 Array Antenna for ETC 
In order to demonstrate the effectiveness and practical applications of the proposed slot-loaded patches, a high-gain planar array antenna composed of 6 X 6 elements is designed and simulated at $5.8 \mathrm{GHz}$ for ETC. Fig. 1 shows our proposed radiating array of 36 elements, which is basically an inset-fed circular patches loaded with a pair of straight slots. In this work, our attention is focused on the bandwidth enhancement of the fundamental mode. Hence, two straight slots instead of right-angle slots are etched close to and parallel with the nonradiating edges of the circular patch for increasing its bandwidth while at the same time preserving its radiation characteristics.

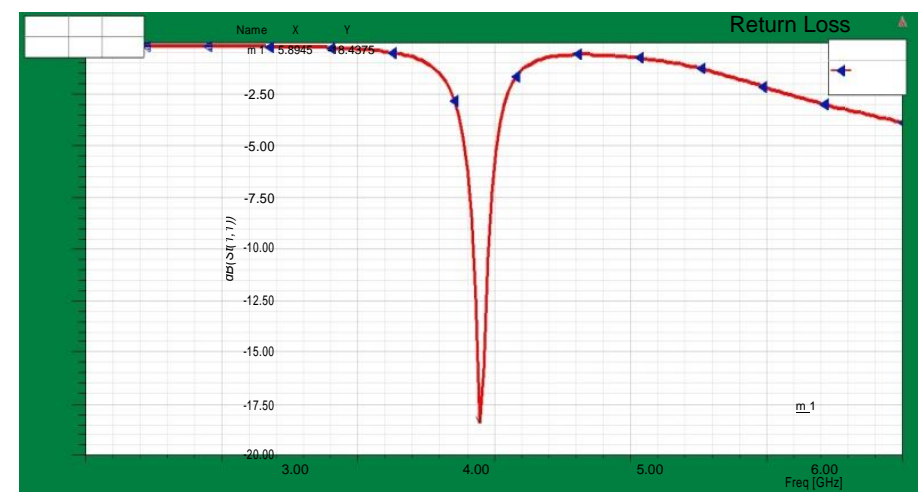

Figure 2Return lossVs Frequency

Fig. 2 shows the return loss curve of the proposed antenna. A return loss of $-18.4 \mathrm{~dB}$ is obtained at $5.8 \mathrm{GHz}$. Fig. 3 shows the input impedances of our proposed radiating elements and that of conventional patches. It can be seen that by etching slots on the non-radiating edges, we can achieve an input VSWR of less than 1.5 over the entire frequency band of interest.

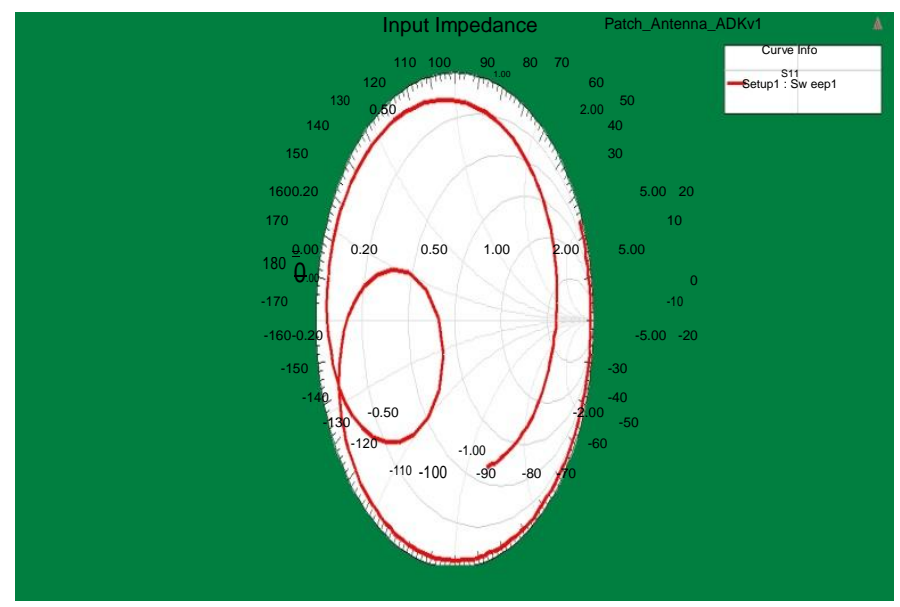

Figure 3 Input Impedance Smith Chart

If a direct EM-simulation is performed for the entire array, there would be a large amount of unknowns, which requires significant computational resources. Therefore, a more efficient design approach was adopted. In this method, an equivalent circuit network was built up by combining the equivalent circuit model of the patch and that of the feeding network. Meanwhile, the mutual couplings among patches can be also considered by incorporating their equivalent circuits. In this work, only the first-order mutual coupling is considered due to its dominance. Subsequently, the input return loss of the array can easily be obtained from the simulation in a commercial circuit simulation package. Furthermore, the radiation performance of the entire array is evaluated by the array factor technique and the array factor is calculated from the scattering parameters of our equivalent circuit network.
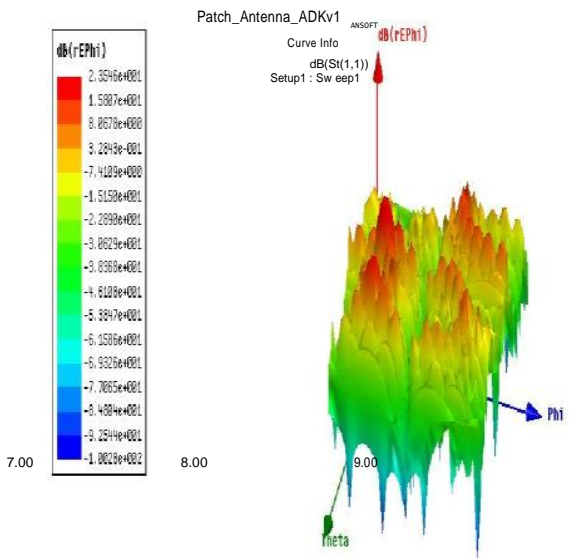

Figure.4 3D-Radiations Pattern in Phi Direction
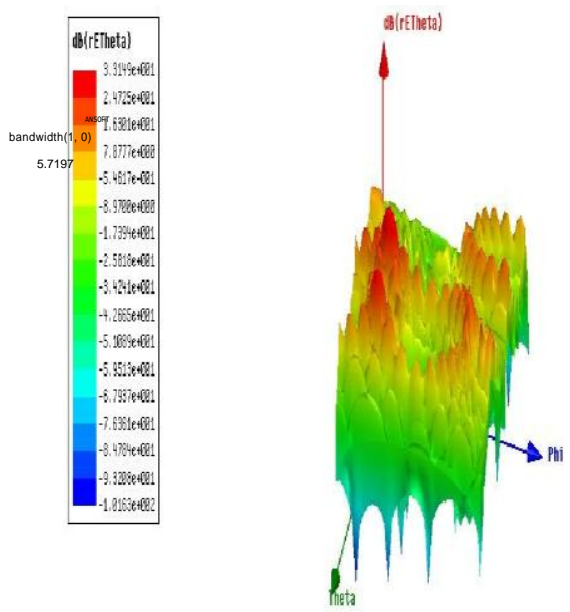

Figure.5 3D-Radiation Pattern in Theta Direction 


\section{CONCLUSIONS}

The Electronic Toll Collection technology concept of prepaying tolls is catching on nationally andglobally. The ETC companies are working on continuing to make ETC attractive to consumers. The present paper is showing the applicability of the antenna for electronic toll collection with moderate high gain and adoptability. The gain of $8 \mathrm{~dB}$ and broad side radiation pattern is giving potential to application of this antenna at the toll gates. More over this technology has to be implemented in India by designing this kind of antennas with the help of computer interfacing through some advanced circuitry.

\section{ACKNOWLEDGEMENTS}

Authors like to express their thanks to the management of MIC College of technology andDepartment of ECE, LBRCE for their continuous support and encouragement during this work. Especially authors like to express their thanks to Dr.LSS Reddy, Director, LBRC of Engineering for providing Excellent R\&D for the completion of this work.

\section{REFERENCES}

[1] Yonghui Wu, Yuanjian Zhang, Fenghua Liu. Electronic Label in Toll Collection. Electronic Technology, 2005(5).

[2] Yong Liu. Introduction to Toll Collection System. Technology of Highway and Transport, 2005(3).

[3] Guguang He, North G Urban Traffic Control System-A General Analysis from the Point of View of Control Theory, Transportation system 1997,2:503-506.

[4] Allen T. Proper, Intelligent Transportation Systems Benefits: 1999 Update, ITS. Program Assessment Coordinator, ITS Joint Program Office. May 1999.

[5] B.T.P.Madhav, Prof. VGKM Pisipati, P.Rakesh Kumar, N.V.K.Ramesh, K.V.L.Bhavani, Sri Jayalakshmi, 8x8 Array Elliptical Patch Antenna on Teflon Substrate Material for WLAN Applications, International Journal of Advances in Science and Technology, Vol. 2, No.5, 2011.

[6] M. Siva Priya Mala, K. Ch. Sri Kavya, Dr. Habibulla Khan, Dr. K.Sarath Kumar , N.Srinija, K. NagendraBabu, K .Prasanthi, M.C.Bharathi, "Computational methods for optimization of linear array antenna" Global Journal of Computer Applications and Technology, GJCAT, Vol 2 (1), 2012, 1005-1010.

[7] K.Ch. Sri Kavya, B. Sri Saila, S.Vasu, Y. N. Sandhya Devi, G. Sudheer Kumar, P. BhanuSrinivas, "Coefficients correction of phased array antenna" Global Journal of Computer Applications and Technology, GJCAT, Vol 2 (2), 2012, 1068-1074.

[8] *B.T.P.Madhav, K. Guru Pavani, M. Raveendra, N. RevanthTeja, "Array Antenna Performance Evaluation Based on Element Spacing between the Patches", International Journal of Emerging Technology and
Advanced Engineering Website: www.ijetae.com (ISSN 2250-2459, Volume 2, Issue 3, March 2012).

[9] B.T.P.Madhav, VGKM Pisipati, Habibulla Khan, VGNS Prasad, P.V.Datta Prasad, P.Sreekanth," MICROSTRIP CIRCULAR PATCH ARRAY ANTENNA FOR WLAN APPLICATIONS ON LIQUID CRYSTAL POLYMER SUBSTRATE", Journal of Emerging Trends in Computing and Information Sciences, ISSN 2079-8407, vol2, no2, Feb11.

[10] http://www.go-etc.jp/english/device/index.html

\section{BIOGRAPHIES}

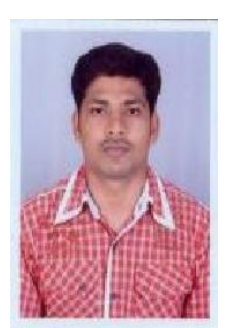

P. Rakesh Kumar Was born in India in 1986. He did his B.Tech From CR Reddy Engineering college and M.Tech from KLC of Engineering. Presently he is working as Assistant professor in the department of ECE of LBR college of Engineering, Mylavaram. $\mathrm{He}$ is having three years of teaching experience and he is having 15 International Journal papers in his credit. His field of interest includes antennas and vlsi design.

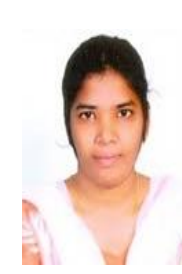

S. Sudharani was born in India in 1986. She did her B.Tech From CR Reddy Engineering college and M.Tech from Balaji institute of technology. Presently she is working as Assistant professor in the department of ECE of MIC college of Technology,kanchikacherla.She is having three years of teaching experience. Her field of interest includes antennas and vlsi design. 